\title{
Los territorios universales del siglo XXI: nueva categoría de la espacialidad (do)minada
}

\author{
Alicia LAURÍN \\ Departamento de Geografía \\ Centro de Estudios de Integración Regional \\ Universidad Nacional del Comahue (Argentina) \\ alaurin_ceir@yahoo.com.ar
}

Recibido: 02-12-2014

Aceptado: 31-05-2015

\section{RESUMEN}

El trabajo llama a una reflexión crítica sobre un aspecto de la realidad social que necesita imperiosamente ser pensada y analizada. Las denominadas Reservas de Biósfera constituyen mecanismos de apropiación para la dominación de territorios que, antes de ser denominados Reserva de Biósfera, se identificaban únicamente como áreas bajo control estatal. Me propongo abordar estas territorialidades como una problemática geopolítica más que ambiental, que revelaría una nueva forma de apropiación de la naturaleza.

Palabras clave: territorio; reserva de biósfera; poder; actores supranacionales; geopolítica.

\section{The 21st Century Universal Territories: New Category of (Do)minated Spatiality}

\begin{abstract}
This paper offers a critical examination on an aspect of social reality that needs to be thoroughly reflected upon and analyzed. The so-called Biosphere Reserves are mechanisms of appropriation for the domination of territories that before being named as such were identified exclusively on the basis of their definition as areas under state control. This article seeks to address these territorialities from a standpoint that reinforces its geopolitical rather than environmental definition - a perspective that will ultimately reveal a new form of appropriation of nature-
\end{abstract}

Key words: territory; Biosphere Reserves; power; supranational actors; geopolitics.

\section{Os territórios universais do século XXI: Nova categoria de espacialidade (do)minada}

\section{RESUMO}

O trabalho convoca a uma reflexão crítica sobre um aspecto da realidade social que deve ser necessariamente pensado e analisado. As chamadas Reservas da Biosfera representam mecanismos de apropriação para a dominação de territórios que, antes de serem denominados Reserva da Biosfera, se identificavam com áreas sob o controle estatal. Proponho abordar estas territorialidades como uma problemática geopolítica mais que ambiental, que revelaria uma nova forma de apropriação da natureza. 
Palavras-chave: território; reserva da biosfera; poder; atores supranacionais; geopolítica.

\section{REFERENCIA NORMALIZADA}

Laurín, Alicia (2015) "Los territorios universales del siglo XXI: nueva categoría de la espacialidad (do)minada”. Geopolítica(s). Revista de estudios sobre espacio y poder, vol. 6, núm. 1, 83-106.

SUMARIO: Introducción. 1. La imaginación geopolítica moderna y los espacios de reserva. 2. Contexto político neoliberal y prácticas discursivas e institucionales. 3. Áreas de Reservas de Biósfera en la Patagonia argentino-chilena. 4. El poder dominante en la construcción de "territorios universales". Corolario. Bibliografía.

\section{Introducción}

El título de este ensayo busca promover la reflexión sobre un aspecto de la realidad social que necesita imperiosamente ser pensada y analizada, desde una mirada despojada de naturalizaciones instaladas como "normales". La categoría que se privilegia en este trabajo es el territorio para llamar la atención sobre formaciones relativamente nuevas creadas a partir del último tercio del siglo pasado.

No se ha oído hablar en el mundo académico de territorios universales, probablemente sea por el significado con el que estamos habituados a identificarlos: territorios estado-nacionales con las propiedades identitarias y geopolíticas que contienen; territorios acotados bajo determinado control; territorios instituidos por prácticas formales o informales, legítimas o no. Se podría seguir incrementando la lista pero no variaría lo que deseo resaltar. En todos los casos transmite la esencia simbólica y material de la exclusividad excluyente. Expresa dominio jurídico y político, en consecuencia tiene que ver con el poder, también con la propiedad y con la posesión.

No voy a referirme al territorio estatal, ese en uno de los múltiples territorios que coexisten en un mismo territorio; tampoco lo pienso como una formación externa a la formación social, sino como mucho más que eso. Concibo al territorio como una entidad construida por actores en interacción histórica con su medio y sustrato físico, que transforman y modifican sucesivamente (Porto-Gonçalves, 2006); una entidad social, material y simbólica construida por todos los actores incluyendo al Estado. Implica un acto de apropiación vinculado al valor de uso que la sociedad asigna a su territorio (para vivir, para producir, para identificarse con su tierra) y un acto de dominación concreta y funcional vinculado al valor de cambio como mercancía, como bien material e intercambiable (Lefebvre, citado por Haesbaert, 2007).

Precisamente el subtítulo de este trabajo hace referencia a un acto de apropiación para la dominación de un territorio que antes de ser denominado Reserva de Biósfera - para mí, Territorios Universales- se identificaba con áreas bajo control estatal 
a través de la institución "Parques Nacionales", frecuentemente localizadas en zonas de frontera, limítrofes con otros países. Áreas de dominación y apropiación estatal, material y simbólica en el pasado de formación de los Estados territoriales. Áreas marginales desde la perspectiva estatal-nacional, ocupadas por sociedades pre-estatales existentes desde tiempos muy anteriores a la implantación de las fronteras nacionales, a integrar a las áreas centrales del país. Áreas de "desierto" desde la misma perspectiva, a ser pobladas cuando ya estaban pobladas por aquellas comunidades.

Me propongo abordar estas territorialidades denominadas "Reserva de Biósfera", como una problemática geopolítica más que ambiental y desde una perspectiva transmoderna, siguiendo a Dussel (2000), que revelaría una nueva forma de apropiación de la naturaleza. La denominación "territorios universales", entidad a la que hago referencia, es una expresión material, espacial y simbólica de la imaginación geopolítica moderna; es una representación espacial de la geopolítica moderna basada en un esquema teórico conceptual que proporciona una visión del mundo como si fuera único y que acompañó el proceso de formación de los Estados-nación y del capitalismo en Europa y en el resto del mundo (Agnew, 2005).

A continuación me referiré a la imaginación geopolítica moderna en un nivel argumental que permita comprender las prácticas espaciales consecuentes. Luego abordaré el contexto político neoliberal en el que comienzan a emerger prácticas discursivas e institucionales a partir de las cuales el problema ambiental se integra a la agenda política mundial. El apartado siguiente se detiene en el análisis de las últimas áreas territoriales de la Patagonia denominadas Reservas de Biósfera, cuya particularidad es la de ser una reserva binacional argentino-chilena, que se extiende en una superficie que supera los 4 millones de hectáreas y alberga una masa biótica de valor incalculable. Finalmente identificaré los actores políticos que tienen la capacidad de construir territorialidades según sus propios intereses y concluiré con una síntesis final que pretende reunir los argumentos principales que explicarían la hipótesis de este ensayo, cual es que la creación de Reservas de Biósfera sería una nueva forma de apropiación de la naturaleza.

\section{La imaginación geopolítica moderna y los espacios de reserva}

Asumo la posición que entiende a la geopolítica como el "examen de los supuestos, clasificaciones y explicaciones geográficas que participan en el diseño de la política mundial" (Agnew, 2005: 6). Esta acepción me permitirá explicar los supuestos sobre los que se asienta la imaginación geopolítica moderna cuya estructura conceptual e ideológica tiene su origen en la modernidad europea. La imaginación geopolítica moderna constituye un cuerpo de teoría y práctica para observar el mundo como un todo, como una unidad, planteada en un solo sentido desde Europa - como si fuera el centro del mundo- hacia el resto, produciendo una imagen 
excluyente de formas de vida concretas, múltiples, diversas, "inventando al otro" en palabras de Castro-Gómez (2000: 246).

Esta noción, en relación con los espacios geográficos de reservas a los que me refiero, permite abordar las fuentes de creación de esas áreas, tales como los Programas sobre el hombre y la biósfera o las Declaraciones y Conferencias mundiales sobre el ambiente y la biodiversidad, como también poner en evidencia el protagonismo alcanzado por las grandes organizaciones multilaterales tales como la Organización de las Naciones Unidas y la UNESCO, entre otras, en el tratamiento de los temas ambientales relacionados con la conservación y el desarrollo. En esos documentos quedan registrados los supuestos de los que se parte y las clasificaciones a las que se arriba, para luego derivar las políticas mundiales en torno al "hombre y la biosfera", tal como establece la denominación de las Naciones Unidas.

Dussel sostiene que para aplicar un análisis alternativo al de la modernidad hay que desmitificarla ya que se percibe a sí misma como una civilización superior, que siente la obligación y exigencia moral de desarrollar al primitivo. De esto se deriva una posición ideológicamente eurocéntrica. Según el autor, el eurocentrismo de la modernidad resulta de haber confundido la universalidad abstracta con la mundialidad concreta hegemonizada por Europa como "centro" (Dussel, 2000: 246).

El eurocentrismo impregna la imaginación geopolítica moderna desvinculada del colonialismo, la otra cara de la modernidad, por tanto oculta la existencia de la otredad, del otro diferente, agravado por la tarea implacable que las instituciones de la modernidad desarrollaron sobre los hombres y su entorno para modificarlo, "civilizarlo" y homogeneizar la sociedad y la cultura.

El proceso de homogeneización de la sociedad, la cultura, la economía, la política, el territorio y la identidad nacional ocultó las lógicas territoriales locales de resistencia al proceso y sus historias regionales. Esto dio lugar a la creación de fronteras para separar lo que en otros tiempos históricos estaba unido: sociedades, caminos, vías de comunicación, territorios... Y todo aquello que no quedó en ese "interior" constituyó la otredad: conflictiva, bárbara, nómada, aislada, desordenada, excluida, desértica o ignorada. La discursividad hegemónica implantaba este imaginario en la sociedad, un imaginario fundante de la identidad nacional. Este proceso en términos políticos y éticos subordinó, colonizó, dominó, generó violencia y resistencias en las sociedades locales. La perspectiva transmoderna, como proyecto emancipador, permite incluir en el análisis la otredad constitutiva de la modernidad, es decir, los "otros", la alteridad.

La visión del mundo planteada desde esa óptica, sin considerar el impacto colonial sobre las sociedades americanas, generó prácticas orientadas al desarrollo y la modernización según pautas disciplinarias a ser cumplidas. Como cuerpo de teoría y práctica desplegándose en un escenario político/económico/tecnológico cambiante, la imaginación geopolítica moderna ha ido adecuándose desde su origen en el siglo $\mathrm{XVI}$, no ha permanecido invariable como tampoco los discursos geopolíticos. Pero no obstante la dinámica de los tiempos y la adecuación de la imaginación geopolíti- 
ca a los cambios, persisten formas vigentes, según Agnew, que señalan su continuidad y ello se ve en la permanencia de los principios básicos:

- Mantenimiento de un lenguaje de diferencias (moderno/atrasado; podríamos agregar rico/pobre, desarrollado/subdesarrollado).

- Concepción del mundo como un todo en tanto que ámbito de referencia para las relaciones interestatales.

- Exclusividad de los Estados territoriales como actores de la política mundial.

- Existencia de la búsqueda de supremacía por parte de las grandes potencias (Agnew, 2005:101-102).

Las prácticas espaciales, en tanto que acciones sobre los territorios derivadas de aquella imaginación geopolítica, producen representaciones espaciales que subordinan los intereses de los lugares y de sus pueblos a los intereses de un conjunto mayor, velado en el caso que analizo, aunque en los Programas el sujeto beneficiario de las intervenciones es la "humanidad". Esto es así porque el poder hegemónico se atribuye la capacidad para diseñar agendas políticas que se imponen a los demás.

\section{Contexto político neoliberal y prácticas discursivas e institucionales}

El rol de la imaginación geopolítica moderna que se corresponde con el neoliberalismo económico, desde la perspectiva que sigo en este ensayo, es clave para explicar la espacialidad de la geopolítica de los recursos naturales. El rasgo principal de este tramo neoliberal es la supremacía que se le otorga al mercado por encima de los Estados; el principio de hegemonía de los Estados ha variado hacia el principio del mercado que impone la lógica del "deber ser"1. Esto implicó abrir las economías nacionales a los mercados; estimular las inversiones extranjeras para la explotación de minerales; privatizar instituciones económicas y de servicios, de propiedad y gestión nacional; en definitiva, instalar lo que tan bien se sintetizó en el axioma "más mercado menos Estado". La geopolítica del neoliberalismo sobre los recursos naturales, según Machado Aráoz, ensayó estrategias desde los centros mundiales de poder para resolver la crisis sistémica de los años 70. Definió otras modalidades de intervención sobre los recursos naturales para reasegurarse el "control, acceso y

\footnotetext{
${ }^{1}$ El autor de referencia explica que la incipiente hegemonía ideológica sin necesidad del Estado preponderante concreto, no marca el "fin de la geopolítica", sino una posible reformulación de un enfoque estadocéntrico a otro que gire en torno a las empresas y las ciudades, a la que algunos Estados deberán adecuarse para disminuir el control sobre los mercados que se les plantea (Agnew, 2005: 12).
} 
disposición de los recursos naturales claves para la reproducción del sistema" (Machado Aráoz, 2011: 151). América Latina fue el escenario de experimentación y consolidación del neoliberalismo. Y ello ha llevado a una intensificación de la demanda de bienes de la naturaleza para incrementar la producción de bienes de consumo para los centros mundiales de consumo y acumulación.

Los lugares poseedores de recursos considerados estratégicos, como el agua dulce, la biodiversidad, el petróleo, el gas y minerales han sido revalorizados por el capital privado nacional y transnacional a través de la financiación de proyectos y programas y su ejecución en aquellos lugares de interés.

En este marco político/económico/ideológico es posible pensar que los mecanismos de apropiación, manejo, conservación y sustentabilidad de los recursos naturales, establecidos sobre las áreas de reserva que he seleccionado en este trabajo, son nuevos territorios incorporados a la racionalidad del capital aunque se sostenga en los programas ambientales que las áreas de reserva de ecosistemas naturales se preservan para el beneficio de la humanidad. Todos los programas ambientales que más adelante analizaré tienen su origen en la década de los años 70; ligados a la geopolítica de los recursos naturales explicarían la invención de nuevas territorialidades.

El neoliberalismo conduce a la formación de estos territorios que denomino universales - lo que ocurrió en un tiempo muy corto- sobre la base de los instrumentos de gestión del ambiente humano a los que haré referencia a continuación. Significó "una vasta reorganización del poder mundial, una redefinición de las estrategias y modalidades de dominación, producidas básicamente a través de la reestructuración de los flujos productivos y comerciales a escala global" (Machado Aráoz, 2011: 154).

La espacialidad de la geopolítica moderna en este tramo del neoliberalismo, toma en nuestro caso de estudio la forma de áreas naturales protegidas, parques, reservas naturales, reservas de biósfera, monumentos naturales o culturales. No dudo de los propósitos sobre un uso equilibrado de la naturaleza para la preservación. Las Reservas de Biosfera como modelo de conservación y desarrollo sostenible/sostenido, sobre la base de las necesidades sociales, culturales, espirituales y económicas de la sociedad, como así también los instrumentos de gestión e intervención, no logran detener la disminución y/o pérdida de la biodiversidad y la pobreza. Tampoco logran detener los ritmos de explotación y transformación de los recursos ni la alarmante situación de la sobreexplotación de la naturaleza, la degradación de suelos, del cambio climático ni el desplazamiento de la población localizada en esas áreas. La conservación de la naturaleza es un proceso político, no sólo un proceso biológico, en consecuencia es un proceso condicionado por el poder, en el que se pone en juego conflictos de intereses.

Los instrumentos de gestión de la naturaleza y el hombre surgieron en paralelo y cumplieron el rol de instalar la problemática ambiental en las agendas políticas del mundo y de diseñar una serie de prácticas promovidas por organizaciones interna- 
cionales como las Naciones Unidas que condujeron a las formaciones territoriales que analizo. Los Estados, las administraciones nacionales y locales, las organizaciones internacionales de financiamiento, las organizaciones científicas, los ciudadanos, las comunidades y las empresas son los actores políticos convocados para ejecutar las normas que deben dictar los Estados y ejecutar los Ministerios de Ambiente y Desarrollo, en el marco de los programas, para asegurar la preservación del medio en beneficio de la sociedad y el cumplimiento de los objetivos que se proponen dichos programas.

Aparece en el escenario político mundial el Programa de las Naciones Unidas sobre el Hombre y la Biósfera (1970), conocido por sus siglas en ingles MaB, luego le sucede el informe sobre los límites del crecimiento $^{2}$ (Informe Meadows, 1972) que sirvió de argumento para el tratamiento y posterior programación de lo que en términos muy genéricos se denomina medio ambiente. Luego sigue la Conferencia de las Naciones Unidas sobre el Medio Humano (1972, Estocolmo) y por recomendación de esa Conferencia se crea el Programa de las Naciones Unidas para el Medio Ambiente (PNUMA), en el que por primera vez el ambiente se constituyó en una cuestión de Estado. Aquí se estableció el derecho de las personas a vivir en un "medio de calidad tal que le permita llevar una vida digna y gozar de bienestar [...]" (Principio 1, Declaración de la Conferencia de las Naciones Unidas sobre el Medio Humano, 1972). El antecedente previo a esos programas es el PNUD, Programa de las Naciones Unidas para el Desarrollo (1965), que comienza a establecer la relación entre desarrollo y naturaleza.

Como se sabe sobradamente, los límites del crecimiento estuvieron explicados por la relación recursos-población-alimentos, recayendo en la dinámica de la variable demográfica la razón del futuro agotamiento de los recursos y alimentos. Como consecuencia de ese informe, la Conferencia de la UNESCO de 1972 aprueba la Convención sobre la Protección del Patrimonio Mundial, Natural y Cultural ${ }^{3}$.

La ciencia colabora en la elaboración del concepto de "reserva de biósfera" (en adelante $\mathrm{RB}$ ) en el marco del programa $\mathrm{MaB}$ recientemente citado. Este programa intergubernamental e interdisciplinario, se puso en marcha con la finalidad de promover la investigación, formación, supervisión y educación en torno a problemas ambientales e impulsar proyectos pilotos en busca de la compensación y el equilibrio entre la responsabilidad humana de mantener la naturaleza y conservar la biodiversidad y, por otra parte, la necesidad humana de utilizar los recursos para mejorar el bienestar social y económico de las poblaciones (citado en la Declara-

\footnotetext{
${ }^{2}$ Recordemos que dicho informe fue solicitado en 1970 por el conocido Club de Roma al Instituto de Tecnología de Massachusetts. El club estaba integrado por empresarios, científicos y políticos interesados en conocer las tendencias y problemas económicos que afectarían a la sociedad global.

${ }^{3}$ Convención disponible en URL: <http://whc.unesco.org/archive/convention-es.pdf $>$. Consultada el $23 \mathrm{de}$ Marzo de 2014.
} 
ción de Madrid sobre el MaB y la Red Mundial de RB, 2008). La Declaración sobre el Medio Humano a partir de la cual se implementa el programa PNUMA proclama que los problemas ambientales son causados por el subdesarrollo, por un lado, y por la industria y el desarrollo tecnológico, por otro. Se resalta en ella la capacidad adquirida por los seres humanos para la modificación de la naturaleza sin distinguir entre poblaciones del mundo industrializado y aquellas del mundo subdesarrollado. En la proclama se señala que ambos tienen cada vez más capacidad de transformación y consumo del medio natural, sin distinguir que los países industrializados tienen una capacidad muy superior de transformación que los países de economías "subdesarrolladas". Los centros mundiales de producción y consumo no son iguales; a través de las profundas transformaciones institucionales y tecnológicas se perpetúa en el presente "la sistemática transferencia de bienes y servicios ambientales desde las sociedades subalternas hacia las dominantes y la localización inversamente asimétrica de los riesgos y costos ambientales de la sobreexplotación de la naturaleza, a través de la «especialización» del Norte en «mercancías tecnológicas» y del Sur en «mercancías naturales»" (Leff, citado por Machado Aráoz, 2010: 45; entrecomillado del autor).

La meta "imperiosa de la humanidad" es la defensa y el mejoramiento de la calidad de vida de las generaciones presentes y futuras, para lo cual se convoca, como ya señalé, a los actores de gestión gubernamental, financiera, científica, económica, política y de la sociedad civil. Del análisis de los instrumentos de gestión citados se desprende que las empresas son los actores menos nombrados para cumplir con las metas propuestas; lo cierto es que en la práctica política se comportan como actores geopolíticos que pretenden asegurarse el acceso, control y gestión de las fuentes contenedoras de recursos naturales y biodiversidad, como explico más adelante.

Continuando con la presentación de los programas, en 1976 se creó la Red Mundial de RB (Red), como un mecanismo definido como esencial para el cumplimiento de los objetivos de programa. La Red está integrada por todas las áreas que los Estados interesados consideran necesario o beneficioso incluir. Así se crea un territorio-red en la que cada RB constituye un nodo de la red mundial. El Estatuto que rige el funcionamiento de la Red, creado en 1996 durante el desarrollo de la Estrategia de Sevilla, establece —entre varios propósitos y mecanismos de gestión- que es un instrumento para la conservación de la diversidad biológica en consonancia con los objetivos y propósitos establecidos en el Convenio sobre la Diversidad Biológica que entró en vigencia en 1993.

La Cumbre de la Tierra celebrada en Río en 1992 introduce la necesidad de conservar la diversidad biológica reconocida como el principal factor para la evolución de la vida en el planeta. La reducción de la diversidad biológica a causa del desarrollo de prácticas humanas moviliza las acciones hacia la conformación de una nueva alianza con los Estados con el propósito de comprometer, a través de la firma del Convenio sobre la Diversidad Biológica (DB), su participación en la conservación de la DB mediante la "utilización sostenible de sus componentes y la participación 
justa y equitativa en los beneficios que se deriven de la utilización de los recursos genéticos" (Día Internacional de la DB, 22 de mayo).

El Convenio cubre la DB a nivel de ecosistemas, especies y recursos genéticos, de biotecnología y de seguridad biotecnológica. Es concebido como un instrumento para gestionar recursos de manera integrada bajo un enfoque sistémico. Conforma un instrumento legalmente vinculante ${ }^{5}$.

A continuación presentaré la última RB designada por la Unesco en la región patagónica para dar cuenta de la dimensión biológica y natural que encierra y el potencial estratégico que posee por la existencia de recursos genéticos y humanos, pero también aspiro a poner en cuestión que la presencia de propiedades privadas en el seno de la RB constituye una fuente de conflicto que evidencia el poder del capital sobre el derecho que otorga la norma al ciudadano, volviendo visible también que de cara al siglo XXI el control de la biodiversidad será unos de los ejes de disputa de poder de los grupos económicos, científico-tecnológicos y de la sociedad civil, tal como lo sostienen numerosos estudiosos del área de la Ecología Política, la Antropología y la Ciencia Política (Leff, 2005; Delgado Ramos, 2013; Alimonda, 2011; Coronil, 2000; Escobar, 2000; Preciado Coronado, 2010; entre otros).

\section{3. Áreas de Reserva de Biósfera en la Patagonia argentino-chilena}

El concepto de RB acuñado por el MaB, como he señalado, hace referencia a zonas de ecosistemas terrestres, costeros marinos o una combinación de ambos ecosistemas. Los Estados miembros de las Naciones Unidas proponen sus áreas para ser reconocidas internacionalmente como tales en el marco del MaB.

América Latina y el Caribe ingresaron al programa el mismo año de creación de la red (1976). En primer término lo hizo Uruguay y progresivamente, hasta el año 2014, casi sin interrupción anual se fueron incorporando el resto de los países. De las 610 reservas del mundo que actualmente existen 117 se localizan en la región. De todos los países del continente, como puede verse en el Cuadro 1, sólo México tiene en su territorio 41 áreas como reservas de biósfera. La Argentina y Chile, que comparten una reserva binacional, son los países que siguen a México con 14 y 10 áreas de reserva respectivamente. Los años 2000 y 2006 se destacan por el elevado número de áreas que ingresaron al programa (11 y 18, respectivamente) en sus 38 años de vigencia.

\footnotetext{
${ }^{4}$ Disponible en URL: < http://www.un.org/es/events/biodiversityday/convention.shtml>. Consultada el 14 de Marzo de 2014.

${ }^{5}$ Ver Convenio sobre la Diversidad Biológica, disponible en URL: < https://www.cbd.int/doc/legal/cbdes.pdf>. Consultada el 23 de Abril de 2014.
} 
Cuadro 1. Reservas de Biosfera en América Latina y el Caribe (año de designación)

\begin{tabular}{|c|c|c|}
\hline Año & Número & Países de pertenencia \\
\hline 1972 & \multicolumn{2}{|c|}{ Conferencia de Estocolmo - $1^{\circ}$ CNUMAD } \\
\hline 1976 & 1 & Uruguay \\
\hline 1977 & 9 & Bolivia; Chile; México; Perú \\
\hline 1978 & 1 & Chile \\
\hline 1979 & 6 & Chile; Colombia; Honduras; México \\
\hline 1980 & 1 & Argentina \\
\hline 1981 & 1 & Chile \\
\hline 1982 & 2 & Argentina; Costa Rica \\
\hline 1983 & 2 & Chile; Panamá \\
\hline 1984 & 4 & Argentina; Chile; Cuba; Ecuador \\
\hline 1986 & 4 & Argentina; Bolivia; México \\
\hline \multirow[t]{2}{*}{ Sub-total } & 31 & \\
\hline & \multicolumn{2}{|c|}{ Informe Brundtland - $2^{a}$ CNUMAD } \\
\hline 1987 & 3 & Cuba \\
\hline 1988 & 2 & Costa Rica; México \\
\hline 1989 & 1 & Ecuador \\
\hline 1990 & 2 & Argentina; Guatemala \\
\hline \multirow[t]{2}{*}{ Sub-total } & 8 & \\
\hline & \multicolumn{2}{|c|}{ Conferencia de Río - Foro de ONGs - Agenda 21} \\
\hline 1992 & 1 & Guatemala \\
\hline 1993 & 6 & Brasil; México; Venezuela \\
\hline 1995 & 3 & Argentina; México \\
\hline 1996 & 1 & Argentina \\
\hline 1997 & 1 & Nicaragua \\
\hline 2000 & 11 & Argentina; Brasil; Colombia; Cuba; Ecuador; Panamá; Paraguay \\
\hline 2001 & 6 & Argentina; Brasil; México; Panamá; Paraguay \\
\hline 2002 & 4 & Argentina; Brasil; República Dominicana; Ecuador \\
\hline 2003 & 3 & México; Nicaragua \\
\hline 2004 & 2 & México \\
\hline 2005 & 2 & Brasil; Chile \\
\hline 2006 & 18 & México \\
\hline 2007 & 8 & Argentina; Chile; Costa Rica; Ecuador; El Salvador; México \\
\hline 2008 & 1 & México \\
\hline 2009 & 3 & México; Venezuela; Brasil \\
\hline 2010 & 7 & Chile; Costa Rica; México; Nicaragua; Perú \\
\hline 2011 & 5 & Chile; El Salvador; Guatemala; Honduras; Perú \\
\hline \multirow[t]{2}{*}{ Sub-total } & 82 & \\
\hline & \multicolumn{2}{|c|}{ Conferencia Río+20 } \\
\hline 2012 & 3 & Chile; Haití; México \\
\hline 2013 & 1 & Ecuador \\
\hline 2014 & 3 & Argentina; Ecuador; Uruguay \\
\hline Sub-total & 7 & \\
\hline Total & 128 & \\
\hline
\end{tabular}

Fuente: Elaboración propia en base a la información de la UNESCO (2013). 
Lo importante no es sólo el número de reservas que cada país tiene sino la biomasa y minerales que contienen y las superficies comprometidas. El Mapa 1 (Chile) y el Mapa 2 (Argentina) muestran las RB en la región patagónica, entre las que destaca una de las áreas más grandes e importantes por la variedad de recursos, que tomaré como ejemplo: la RB binacional argentino-chilena, cuya área argentina se denomina RB Andino Norpatagónica y cuya área chilena es la RB Bosques Templados Lluviosos de los Andes Australes.

Mapa 1. RB en Chile

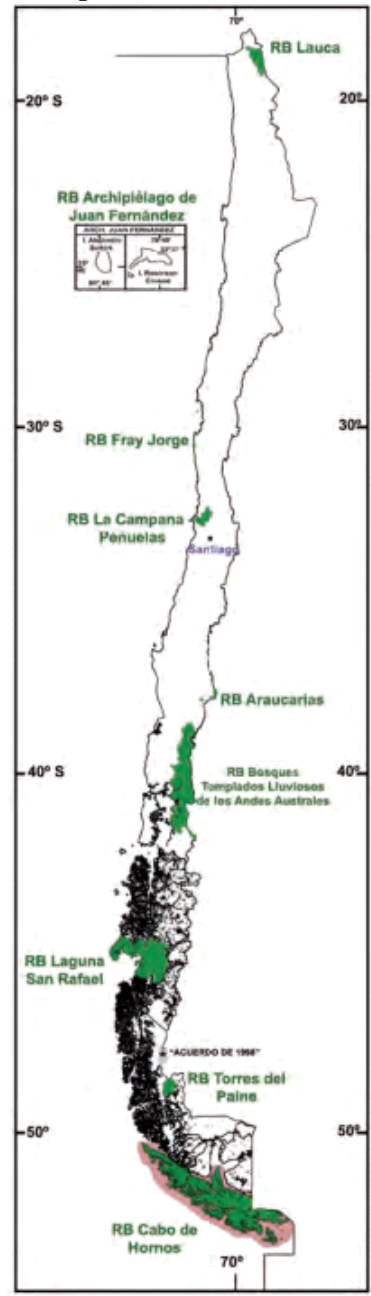

Fuente: Araya Rosas (2009).
Mapa 2. RB en la Patagonia argentina

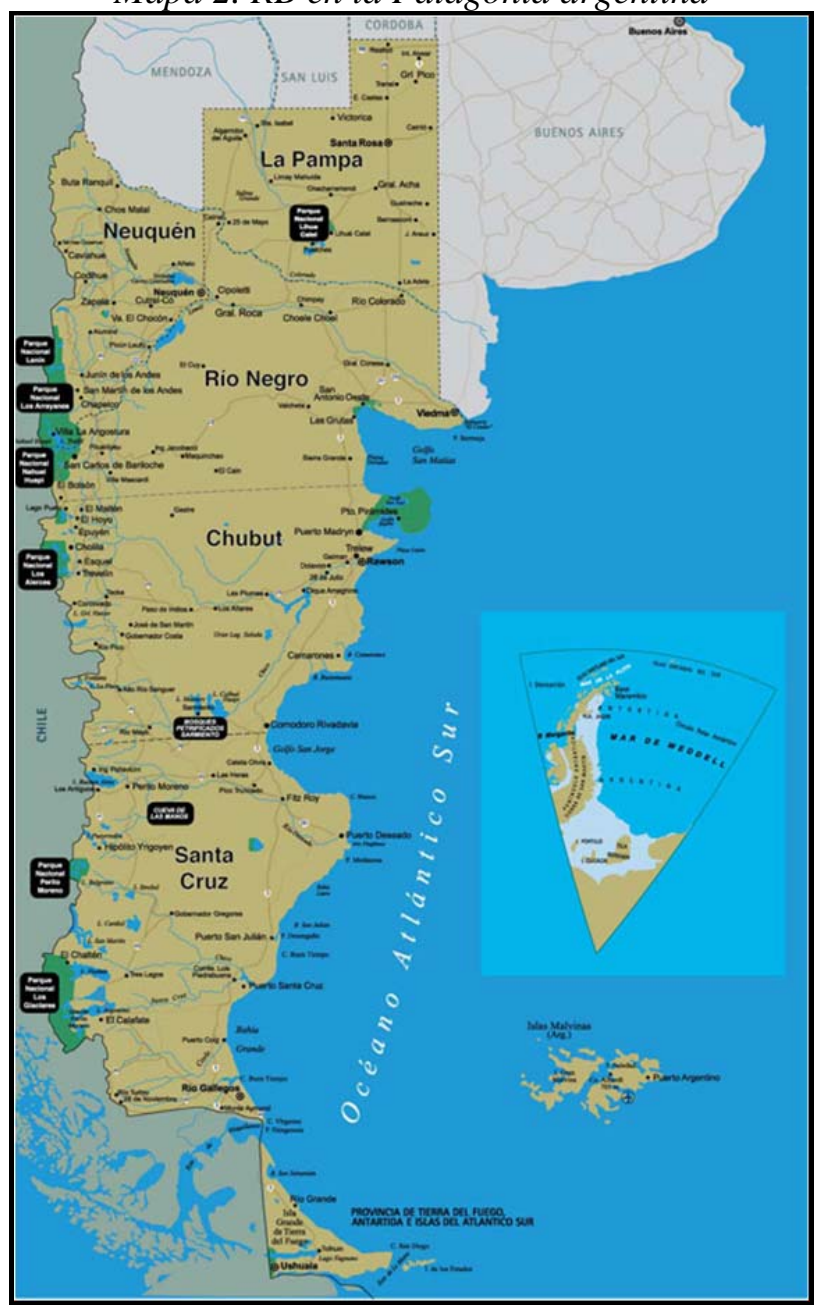

Fuente: <www.argentinaturismo.com.ar>. 
La RB Andino Norpatagónica abarca una superficie de 4,5 millones de ha e incluye diez parques nacionales, de espesos bosques de alerces, lengas, arrayanes, coihues, raulí, roble pellín, araucarias, maitenes; arbustos y flora que se corresponden con las abundantes precipitaciones del área; una flora y fauna riquísimas; más de diez lagos y numerosos ríos y lagunas. Contiene el $40 \%$ de la superficie total de bosques templados lluviosos del planeta y según la fuente consultada (Jefatura de Gabinete de Ministros. Secretaría de Ambiente y Desarrollo Sustentable de la Nación, 2014) constituye una reserva con escasa intervención humana. Como se puede apreciar en el Cartograma 1 conforma una monumental reserva de recursos naturales y paisajísticos; 2,3 millones de ha aproximadamente están localizadas en territorio argentino y poco más de 2 millones en territorio chileno.

\section{Cartograma 1. La RB binacional argentino-chilena}

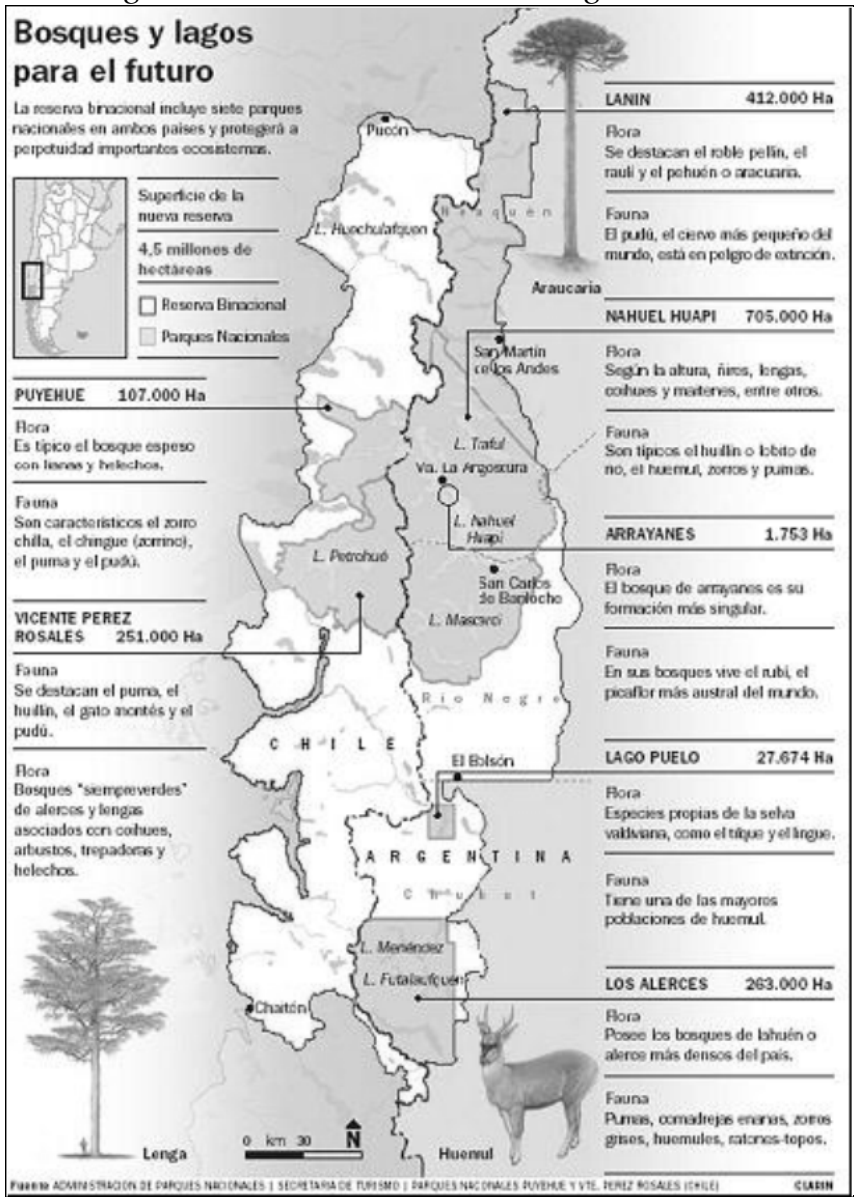


En el interior de la reserva Andino Norpatagónica coexisten los Parques Nacionales - algunos pertenecientes a la categoría de Patrimonio de la Humanidad- y las áreas de Reserva Natural protegida por la administración provincial; también tierras fiscales de propiedad de los Estados nacionales y locales, y tierras de propiedad privada. De norte a sur se destacan los Parques Nacionales Lanín, Nahuel Huapi, Los Arrayanes, Lago Puelo y Los Alerces en la porción argentina. El área chilena se denomina RB Bosques Templados Lluviosos de los Andes Australes, y abarca los Parques Nacionales Villa Rica, Puyehue, Vicente Pérez Rosales, Alerce Andino y Hornopiren. Incluye también, como en Argentina, numerosas Áreas Naturales Protegidas y Reservas Naturales.

Como área de biósfera cumple la función de reserva para la conservación y preservación del ecosistema. Para ello se desarrollan una serie de prácticas programadas de acuerdo a la zonificación propuesta para el cumplimiento de su función entre las que se incluyen prácticas de conservación, acciones para el desarrollo económico y humano y apoyo logístico para los proyectos de demostración, educativos, de capacitación, investigación y observación permanente en relación con cuestiones sociales, regionales, nacionales y mundiales de conservación y desarrollo. Si bien el Estatuto de la Red Mundial de Reservas propone a esas acciones como "funciones" que cumplen las RB, en realidad cumplen la única función de reserva ya que todas esas prácticas conducen a la preservación y conservación ${ }^{6}$. Así se encuentra en la reserva una zona núcleo que "tiene que estar protegida legalmente y debe asegurar la protección a largo plazo del paisaje, los ecosistemas y las especies que contiene. Debe ser suficientemente grande para garantizar los objetivos de la conservación. [...] Normalmente, la zona núcleo no está sometida a las actividades humanas, excepto para la investigación y el seguimiento, y como podría ser el caso, para usos extractivos tradicionales por parte de las poblaciones locales o para actividades de recreación" (Jefatura de Gabinete de Ministros. Secretaría de Ambiente y Desarro1lo Sustentable de la Nación, 2014: 1); una o más zonas de amortiguación, circundante a la zona núcleo, donde se practican actividades compatibles con los objetivos de la conservación que no obstaculicen la conservación de la zona núcleo, puede proveer apoyo para actividades educativas, de recreación y turismo; y una tercera zona exterior de transición donde se fomentan y ejecutan formas de explotación de los recursos, se pueden localizar asentamientos humanos, desarrollar actividades agrícolas, ganaderas, forestales y de aprovechamiento de fauna y flora. En esta zona las comunidades locales, los organismos de conservación, los científicos, las asociaciones civiles, las empresas privadas y otros interesados deben trabajar en conjunto "en tareas de gestión y desarrollo sostenible de los recursos de la zona para el

6 Estatuto de la Red Mundial de Biosfera, art. 3. Disponible en URL: $<$ www.unesco.org/new/es/natural.../man-and-biosphere-programme>. Consultada el 12 de Marzo de 2014. 
beneficio de sus habitantes" (Jefatura de Gabinete de Ministros. Secretaría de Ambiente y Desarrollo Sustentable de la Nación, 2014: 1).

En territorio argentino, esta reserva se extiende por tres provincias: de norte a sur, Neuquén, Río Negro y Chubut, con importantes localizaciones urbanas con área de influencia de alcance regional, tales como Aluminé, Junín de los Andes, San Martín de los Andes, Villa La Angostura (Provincia de Neuquén); San Carlos de Bariloche, El Bolsón (Río Negro); Lago Puelo, El Hoyo, Esquel, Trevelín, Epuyen y Cholila (Chubut). En territorio chileno se extiende en las regiones IX y X de Los Lagos y de Los Ríos, respectivamente, desde el sur de la región de La Araucanía.

Confluyen en el juego de intereses en primer término la UNESCO, principal organismo que cumple la función, por medio del PNUMA, de control de gestión y monitoreo sobre la RB; la Red Mundial de RB; y entidades privadas asociadas para el desarrollo de actividades de conservación, de gestión, de uso de bienes y servicios prestados por el ecosistema. Las entidades de financiamiento pueden ser empresas multinacionales que bajo la figura de Responsabilidad Social aportan fondos de manera directa o indirecta; instituciones nacionales públicas y privadas; instituciones financieras internacionales tales como el Banco Mundial, Fondo Mundial por el Medio Ambiente, el Banco Interamericano Desarrollo (BID); los gobernadores de provincias, los intendentes y sus comunidades; instituciones tales como la Administración de los Parques Nacionales, la Secretaría de Ambiente, la Secretaría de Turismo, entre otras. Al superponerse con la zona de Seguridad de Fronteras es probable - aún no lo he corroborado- que intervengan los organismos nacionales de defensa de ambos países. En conjunto conforman una compleja realidad de convergencia política multiescalar cuya gestión está controlada por una organización internacional, las Naciones Unidas.

La idea núcleo de la concepción de RB para el siglo XXI que se propone el MaB es asignarle la función de contribuir a responder a las necesidades de la sociedad en su conjunto (universalidad) no sólo a las comunidades locales. Para ello se determinaron diez directrices que, desde mi perspectiva, no hacen más que reforzar la territorialidad que denomino "territorios universales" por la desigual relación de fuerzas entre los actores. Por ejemplo la octava directriz propone: "Propiciar la administración de cada reserva de biósfera esencialmente como un «pacto» entre la comunidad local y la sociedad en su conjunto"; se aspira a una administración más abierta, evolutiva y adaptativa, porque permitirá asegurar a la reserva y a sus comunidades locales "mejores condiciones para responder a las presiones externas de índole política, económica y social" (Reservas de Biósfera: Estrategia de Sevilla y el Marco Estatutario de la Red Mundial $\left.{ }^{7}\right)$. Finalmente, falta agregar que los proyec-

\footnotetext{
${ }^{7}$ Disponible en URL: <www.unesco.org/new/es/natural.../man-and-biosphere-programme $>$. Consultada el 12 de Marzo de 2014].
} 
tos de desarrollo para esas áreas no deben atentar contra los recursos de la reserva; el ingreso al Programa implica en consecuencia que esos proyectos quedan bajo la evaluación y aceptación del Programa para el uso de los recursos propuestos (Cordero, 2006).

\section{El poder dominante en la construcción de "territorios universales"}

Como ha señalado Machado Aráoz (2011) el trasfondo de la cuestión ambiental se remonta a la crisis del régimen de acumulación de posguerra ${ }^{8}$, que se explica por la crisis de recursos naturales disponibles.

Al vincular el capitalismo con el colonialismo, como lo hace Coronil (2000: 246), "es posible comprender el papel de la naturaleza en la formación de riqueza" y es posible también identificar los agentes del capitalismo en el mundo. Afirma Coronil que "incluir la tierra en la dialéctica capital/trabajo nos permite conocer que el proceso de la creación de riqueza implica un intercambio transformativo entre los seres humanos y el mundo natural del cual forman parte" (2000: 246); significa entonces que la naturaleza no es sólo un factor de producción sino también factor de riqueza. La división internacional del trabajo, bajo esta concepción, implica de manera simultánea un reparto de naturaleza, según explica el autor de referencia. Este aspecto no es tenido en cuenta en las propuestas de las instituciones que he analizado para estas áreas, al menos la realidad muestra que esas áreas de reserva son utilizadas con fines productivos o especulativos por los capitales transnacionales, como más adelante mostraré.

Los programas que he citado no dejan ver los alcances de la nueva funcionalidad asignada a estas áreas desde instituciones sin arraigo territorial, instituciones internacionales constituidas por todas las naciones del mundo (ONU), transformándolas en espacios unifuncionales (reservas de biosfera). La estrategia de refuncionalizar territorios "sirve para la no apropiación de los que construyen territorio vivido; del tiempo vivido" según Lefebvre (citado en Haesbaert, 2007: 21); así cuanto más el espacio es funcionalizado más es dominado por los agentes que lo manipulan volviéndolo unifuncional.

$\mathrm{Y}$ esto conduce a la construcción de territorios de desigualdad que surgen de procesos de dominación funcional; produce territorialidades sin territorios derivados de procesos de dominación simbólica, en términos de Haesbaert (2007).

\footnotetext{
${ }^{8}$ Horacio Machado Aráoz (2011) brinda una explicación muy clara sobre las transformaciones estructurales a partir de la recomposición del esquema de dominación y acumulación global del último tercio del siglo XX. $\mathrm{Si}$ bien es un fundamento para explicar el auge del boom minero de los 90 en América Latina, no hay dudas que ese proceso abarca a todos los recursos naturales. Seguiremos al autor para contextualizar el recorte territorial que buscamos explicar.
} 
La noción de territorialidad remite a la acción de construir territorialidad, a la noción de territorializar acciones. $\mathrm{Y}$ en ese punto, las acciones o las prácticas no son sólo prerrogativas de un Estado sino de un conjunto de actores entre los cuales el Estado es uno más, aunque obviamente con atributos diferenciales cada uno de ellos. He sostenido que los territorios condensan la historia de los vínculos que la sociedad ha mantenido con sus recursos materiales e inmateriales, físicos y naturales, y con la misma sociedad. La configuración espacial no es más que la sucesiva metamorfosis del territorio en el tiempo, apropiado y transformado técnicamente, para satisfacer las necesidades humanas (Laurín et al., 2012). Ello denota la existencia de actores, de una estructura social y de un territorio, con lo cual el territorio no es la base de las acciones sino un elemento enlazado a la estructura social y a los actores. Las territorialidades se construyen en un proceso no lineal, contradictorio y conflictivo; se activan y desactivan en el tiempo (Zusman, 2010).

Por consiguiente, la noción de territorialidad relacional, temporal y plural permite poner de relieve el juego de las múltiples relaciones que se establecen en la construcción de territorialidades. Y también posibilita detectar las acciones de los actores participantes en el juego de intereses que se entretejen alrededor del acceso y apropiación, material y simbólica, de los contenidos materiales del territorio. Así, entonces, si el territorio es una obra humana no se puede/debe desvincular las acciones humanas de la política. No hay acción que no sea política. La política es la mediadora entre el poder y el territorio. Lleva implícita intencionalidades representativas de los actores en juego, que es lo que he querido demostrar al recurrir a la imaginación geopolítica moderna. En consecuencia, la política no es más que la espacialización del poder. Pero no estamos pensando en el poder hegemónico, sería un error analítico suponer que es el único poder; por el contrario, tal como señala Agnew "todas las prácticas sociales implican la utilización de poder, es decir, la capacidad de abordar acciones encaminadas a la realización de objetivos socialmente aprobados (poder para)" (2005: 63). Desde esta perspectiva, la política la concebimos, junto con la autora de referencia, en sus dos dimensiones: la institucional en la que se inscriben los gobiernos y el conflicto de intereses como fundamento de la sociedad civil (Castro, 2005: 92 y 288). Esta doble dimensión de la política nos permite poner en situación relacional las instituciones políticas cuyas acciones afectan diversas instancias de la sociedad y las fuerzas fundacionales ejercidas por actores organizados para institucionalizar sus demandas en los límites de un territorio (Castro, 2005: 93).

La conformación de áreas de reservas entendidas como territorio, desde la perspectiva planteada, contradice en su origen el planteo que estoy desarrollando. Estas territorialidades son derivaciones de una política planteada en un solo sentido, desde organizaciones supranacionales hacia una supuesta sociedad humana, en beneficio de ella y de las generaciones futuras, pero impuestas y definidas según disposiciones derivadas de acuerdos, normas estatutarias y principios básicos a ser aplicados en esas áreas denominadas, por las mismas instituciones: reservas de 
biósfera. Contribuyen al afianzamiento del poder territorial de los actores hegemónicos (las empresas, los organismos de financiación, las ONGs;) en el manejo de los recursos naturales, como explicaré a continuación.

Afirmé recientemente que cuando los espacios son resignificados para el cumplimiento de una única función, producen territorios de desigualdad que desplazan en la práctica - no en el discurso como lo he querido destacar al abordar y citar algunos de los objetivos relevantes - a una parte de los actores que desde la perspectiva que desarrollo también son constructores de territorialidad: los pobladores del lugar, arraigados a sus lugares, desarrollando sus prácticas económicas y sus vidas cotidianas para la satisfacción de sus necesidades materiales. La mayoría de los movimientos sociales surgidos a partir del momento en que la problemática ambiental se transformó en cuestión, se organizaron en torno al acceso a los recursos: suelo, territorios, recursos, servicios, es la evidencia más clara de la afirmación que he realizado.

Se pueden mencionar sólo algunos casos de la región para ilustrar lo que no visibilizan los programas en favor de la humanidad o bien lo que producen. Comenzaré a citar algunas problemáticas de México, Argentina y Chile, que son los países que figuran entre los que más áreas bajo reserva tienen en la región, aunque también debo decir que no es sólo una problemática de estos países, también afectan a otros países de la región aunque las áreas protegidas no constituyan RB.

Un caso se localiza en Chiapas (México), en la RB de los Montes Azules de la selva Lacandona. Aquí la relación conflictiva comienza a emerger entre el poder económico, el poder político y los pobladores locales. Antes de la creación de la RB (1978) más de 50 comunidades indígenas obtuvieron tierras del Estado para el desarrollo de sus actividades productivas. En 1974 se localiza en el área la Compañía Industrial Forestal Lacandona S.A. (sociedad paraestatal, según Martinelli, 2004) para la producción forestal. Esta zona, ya en conflicto por problemas de reparto agrario, fue designada en 1978 como RB. La empresa continuó desarrollando sus actividades dentro de la reserva; el poder político espera recuperar estas áreas de "alta ingobernabilidad" para que la inversión privada invierta en la zona. Organizaciones internacionales ambientalistas inician campañas públicas para pedir el desalojo de las comunidades (Martinelli, 2004).

También podemos asociar estas áreas de $\mathrm{RB}$ al desarrollo de proyectos mineros transnacionales. Para el caso de Argentina, la RB de San Guillermo, en la provincia de San Juan, alberga en su área de reserva a la empresa minera Barrick, cuestionada por el manejo poco "conservador" de la biodiversidad en la explotación de la mina Pascua Lama. En la RB Andino-patagónica, a la que hice referencia, "todos los proyectos del distrito minero andino" de la provincia de Río Negro están localizados en áreas de la reserva. La Asamblea de Vecinos Autoconvocados contra la Megaminería de la ciudad de San Carlos de Bariloche sostiene, en base a la documentación presentada en la legislatura rionegrina por la autoridad de Minería provincial, que con posterioridad a la fecha de denominación de RB se produjeron 
nuevas concesiones mineras y las pre-existentes no cesaron en su actividad, como era de esperar. La preocupación fue presentada a la Administración de Parques Nacionales, institución que interviene en el control de manejo del parque.

En territorio chileno numerosas acciones colectivas del pueblo mapuche en torno a la recuperación de tierras, territorios y bienes naturales son representativas del conflicto que enfrenta la comunidad al Estado, las empresas nacionales y transnacionales, especialmente cuando se trata de área de reserva. Es un conflicto material generado por las políticas extractivistas que desplazan a la comunidad e impiden la reproducción social del pueblo y un conflicto también simbólico por los efectos negativos generados por las empresas forestales, mineras, salmoneras, energéticas y los proyectos de infraestructura y comunicaciones (Pineda, 2012).

Una serie de sucesos localizados en el sector de más alta concentración de biosfera ilustra sobre la desequilibrada relación entre las propuestas/objetivos de los Programas y los resultados esperados, que se produce cuando los intereses de la propiedad privada en áreas de RB se interponen como un elemento dominante, que convierten a estos territorios en territorios de dominación por el derecho que la propiedad les otorga. Uno de esos sucesos ocurre en torno al uso y manejo del agua de la cuenca del río Puelo, compartida por los dos países. El río tiene sus nacientes en el lago homónimo, localizado en la provincia de Chubut (Arg.), y su desembocadura en el seno del Reloncaví, en territorio chileno. Por esta particularidad se convierte en una cuenca hídrica compartida entre las dos jurisdicciones nacionales y está sujeta a protocolos que reglamentan el uso conjunto y a los que establecen el Programa MaB por su condición de RB. Además del lago Puelo integra la cuenca del lago Escondido también en territorio argentino y según la zonificación de las $\mathrm{RB}$ ambos lagos conforman el área Núcleo $\mathrm{N}^{\circ}$. 16, una porción de la zona de amortiguación contigua y la zona Núcleo $\mathrm{N}^{\circ}$. 17, denominada Cerro Cuevas-Arroyo Agujas. Toda la cuenca cubre una superficie de aproximadamente 800.000 ha, la mayor parte (580.000) en territorio argentino. El 80\% de las aguas de esta cuenca y otras aguas de la Región de Los Lagos es de propiedad privada.

El conflicto suscitado tiene varias aristas, una se relaciona con el acceso a la propiedad del agua ${ }^{9}$, otra con el destino del agua o su utilización según fines industriales ${ }^{10}$, otra relacionada con las actividades económicas, predominantemente

\footnotetext{
${ }^{9}$ El Código de Aguas (1981) de Chile define al agua como un bien nacional de uso público y como un bien económico, lo que faculta su gestión según las pautas y códigos de la propiedad privada. Los derechos de agua son concedidos gratuitamente y a perpetuidad a los agentes privados. La libre competencia entre los distintos usos y derechos de propiedad del agua ha favorecido la concentración de la propiedad en los sectores considerados los "motores" del desarrollo nacional: eléctrico, minero y exportador (Larraín, 2006).

${ }^{10}$ El Código de Aguas vigente creó una nueva categoría de derechos: consuntivos y no consuntivos. El primero se refiere al derecho de consumo de aguas, sin que puedan reutilizarse superficialmente, por ejemplo para riego, minería, industria y uso doméstico. El segundo se refiere a aquellos que se solicitan para utilizar
} 
rurales, eco-turistas y turísticas y, aunque solo haré esta breve mención, la del conflicto de intereses entre las autoridades argentinas y chilenas por las políticas unilaterales para el aprovechamiento con fines hidroeléctricos del río sin acuerdos previos ni consultas a los funcionarios argentinos, que merecería una investigación que excede los propósitos de este trabajo.

En el primer caso el acceso a la propiedad del agua habilita a las empresas a desarrollar proyectos hidroeléctricos; en el caso que analizo se propone la construcción de la obra El Portón para la generación de energía para altos consumidores tales como las mineras, las pasteras y las empresas forestales. La empresa oferente es la multinacional energética ENDESA de Chile, subsidiaria de la española de igual nombre. Esta obra afectará la cuenca hídrica del río ubicada mayoritariamente en territorio argentino como ya he dicho y en jurisdicción del Parque Nacional Puelo $^{11}$. Los habitantes del lugar, dedicados predominantemente a las actividades rurales y al eco-turismo, serán o desplazados o bien afectados por la alteración del paisaje que es el principal elemento de atracción turística, entre otros perjuicios. La Campaña Patagonia sin Represas, propuesta por vecinos de los lugares afectados es elocuente de la preocupación que genera en la población, ya que se han nucleado numerosos movimientos sociales que reivindican sus derechos tales como Mujeres sin Fronteras, Corporación Puelo, Ecosistemas, Sociedad Ecológica Regional de El Bolsón, La Asamblea contra el saqueo y la megaminería del Lago Puelo, Por el Agua y la Tierra en Mallín Ahogado, entre otros (Chiappe, 2014).

En el Lago Escondido el problema se genera con el magnate Joseph Lewis, propietario de 14.000 ha que bordean la totalidad del lago. Según la fuente consultada, no sólo controla el acceso al lago sino que pretende construir una represa hidroeléctrica para venderle la energía al Estado. Sobre el Lago Espejo que es el Núcleo de Reserva $\mathrm{N}^{\circ}$. 8, localizado a $80 \mathrm{~km}$ al norte de Villa La Angostura, con la autorización de Parques Nacionales, los dueños de la única hostería del lugar cerraron al público el acceso a la playa ${ }^{12}$.

La estancia La Primavera, del magnate de la CNN Ted Turner, localizada dentro de Parque Nacional Nahuel Huapi "mantiene a los pobladores cautivos en sus propios campos", impide no sólo el acceso ("encadenado") a los ríos Minero y Traful, sino también salir libremente de sus tierras sin la obligación de solicitar permiso, sortear tranqueras con candado y puente enrejado. Hacia el sur, en el área

el agua sin consumirla, como es el caso de los proyectos hidroeléctricos. Este derecho obliga a devolver las aguas a los ríos, sin perjudicar a los usuarios existentes aguas abajo.

${ }^{11}$ Para una mayor explicación consultar el Proyecto de Comunicación del Senado de la Nación Argentina, disponible en URL: <www.senado.gov.ar/parlamentario/307844/download.Pdf $>$. Consultada el 22 de Julio de 2011.

${ }^{12}$ Ver URL: <www.clarin.com/sociedad/acceso-costas-rios-lagosrestringido_0_779322149.html>. Consultado el 12 de Marzo de 2015. 
de núcleos urbanos de la RB, en la provincia del Chubut, los habitantes de El Maitén perdieron la segunda salida de la ciudad por la ruta provincial $\mathrm{N}^{\circ}$. 4, debido a que la propiedad del Grupo Benetton (magnate italiano vinculado a la industria textil, entre otras actividades económicas) ocupa casi una cuarta parte del curso superior del río Chubut, impidiendo el acceso al río y la salida por la mencionada ruta $^{13}$.

Desde el punto de vista del aprovechamiento turístico, estos espacios privados, de naturaleza cercada, se promocionan como cotos de caza, de pesca, o como condominios cerrados, ofreciendo privacidad y exclusividad, especialmente a turistas extranjeros ${ }^{14}$.

También se puede hacer referencia a otros países de la región, tales como Ecuador y el conflicto que las comunidades del Parque Nacional de las islas Galápagos enfrentan, al quedar excluidos del manejo de sus recursos a partir del momento en que se convierte en espacio de reserva y pierde su condición de espacio abierto (Celata y Sanna, 2010). La Amazonia central no queda fuera de las áreas en disputa por el uso y manejo de la biodiversidad.

\section{Corolario}

En consideración a los innumerables conflictos sociales en relación a la existencia de áreas de reserva de naturaleza (y otras formas de protección y conservación), en un contexto caracterizado por la radicalización de la apropiación y explotación de los recursos de la tierra en manos de empresas capitalistas transnacionales, quisiera poner en duda la existencia de los programas ambientales como garantía de preservación de naturaleza. Persisten en los documentos de los Programas a los que hice referencia abundantes propósitos, propuestas, acciones, estrategias muy cercanas a la colonialidad del poder y del saber. Los objetivos de educar y capacitar para la preservación y el buen manejo son conducidos por los que "saben", y ese no es el pueblo o la comunidad ${ }^{15}$; las instituciones convocadas para la cooperación económica son el Banco Mundial, el Fondo Monetario Internacional, el Fondo Mundial

\footnotetext{
${ }^{13}$ Ver URL: < http://tiempo.infonews.com/nota/68902>. Consultado el 13 de Marzo de 2015.

${ }^{14}$ La relación entre localización del capital transnacional productivo y financiero en los Núcleos de Reserva de las RB, en contradicción con las funciones asignadas a esas zonas por el Programa MaB, es un aspecto que aún debe analizarse en profundidad para poder cartografiar y fundamentar las afirmaciones sobre los casos que ilustran este ensayo.

${ }^{15}$ La nueva Estrategia Sevilla del año 1996 incluye en su planteamiento recién para el siglo XXI la conservación del conocimiento tradicional y los recursos genéticos, "cuya función en el desarrollo sostenible debe ser reconocida y estimulada" (Estrategia Sevilla, propuesta 7, pág. 6). Disponible en URL: $<$ www.unesco.org/new/es/natural.../man-and-biosphere-programme>. Consultada el 12 de Marzo de 2014.
} 
para el Medio Ambiente y Organizaciones internacionales no Gubernamentales para la conservación como por ejemplo Conservation International, Worl Wildlife Fund y The Nature Conservancy. También está presente la organización de las Naciones Unidas, principal organización que se reserva el control de la gestión y monitoreo de las RB, que aplican los Estados miembros y que asigna a los Estados la función de relevamiento de áreas, ejecución y control de prácticas y manejo, diseño y aplicación de políticas de protección, preservación, revalorización, entre otras.

En el marco de la hipótesis de este ensayo no es muy osado pensar que estos espacios de reserva de biosfera, que son también reservas de recursos, puedan convertirse en instrumentos de hegemonía, tal como sostiene Escobar (2000). Inclusive se podría aventurar que las Reservas de Biósfera son fracciones territoriales sin espacio y sin tiempo, como los espacios de la globalización. La denominación de "reserva" sustrae del análisis la categoría "lugar", como el intermedio entre el mundo y el individuo, en términos de Santos (1996), transformándose de este modo en algo que es "universal", es decir de toda la humanidad. Sin dudas los conflictos que se suceden en torno a la explotación y al acceso de los recursos señalan muy claramente quienes quedan excluidos.

En síntesis, y volviendo a las RB, teniendo en cuenta el volumen comprometido como reserva, las funciones atribuidas, los actores autorizados, el rol de los Estados y de los organismos internaciones sobre estas áreas, en un contexto caracterizado por un intensísimo uso de los recursos naturales y un despliegue de estrategias para "reservarlos" para el futuro, es necesario recuperar el dominio simbólico y estratégico de estas áreas y asumir una actitud más crítica sobre el dominio material de esas monumentales RB. En los temas ambientales es ineludible el papel que juegan los Estados ya que son los responsables de los lineamientos macropolíticos de la gestión ambiental de los territorios (Alimonda, 2000).

Pero también es necesario el análisis científico crítico de las Ciencias Sociales para producir conocimiento sobre "la formación de poderes hegemónico y de contrapoderes desafiantes" (Alimonda, 2000: 45) en torno a la construcción de territorios y gestión y dotación de recursos naturales.

Finalmente, diré que la noción de globalización asociada a naturaleza es una noción sin territorio, sin tiempo, homogenizadora, transfronteriza que ha instalado conceptos que reemplazarían como tendencia el lugar por lo global; el hombresociedad por humanidad; el territorio por reserva; lo local por medioambiente.

No desconozco la existencia de la globalización, lo que quiero resaltar es que oculta la particularidad o bien la diferencia y la distinción de cada lugar. En el tema de las territorialidades universales el desplazamiento del concepto "lugar", tiene profundas y complejas implicaciones; el lugar no es ni más ni menos que donde se localizan las políticas, donde se arraigan para intervenir en su contenido socialmaterial-natural, donde se localiza el desarrollo, donde la sociedad actúa y construye territorio, donde se desarrollan los contrapoderes desafiantes (de las comunida- 
des) y donde pueden encontrarse nuevas territorialidades con valores emancipatorios (Porto-Gonçalves; 2006).

\section{Bibliografía}

Agnew, John (2005) Geopolítica: una revisión de la política mundial. Madrid: Trama Editorial.

Alimonda, Héctor (2011) "La colonialidad de la naturaleza. Una aproximación a la Ecología Política Latinoamericana", en H. Alimonda (coord.) La Naturaleza colonizada. Ecología política y minería en América Latina. Buenos Aires: Ediciones CICCUS, 21-60.

Araya Rosas, Pedro (2009) "El modelo de reserva de biósfera e instrumentos para su utilización sostenible. El caso de Chile". Programa de Cooperación Sur-Sur. Documento de trabajo No. 39, 2009. Gobierno de Chile. Ministerio de Agricultura CONAF. Universidad de las Naciones Unidas. Academy of Sciences for the Developing Word. [Disponible en URL: <www.conaf.cl/wpcontent/files_mf/1363982052wp39Final2.pdf>. Consultado el 12 de Marzo de 2011].

Castro-Gómez, Santiago (2000) "Ciencias sociales, violencia epistémica y el problema de la «invención del otro»", en E. Lander (comp.) La colonialidad del saber: eurocentrismo y ciencias sociales. Perspectivas Latinoamericanas. Buenos Aires: CLACSO, 145-161. [Disponible en URL: $<$ http://bibliotecavirtual.clacso.org.ar/ar/libros/lander/dussel.rtf $>$. Consultado el 12 de Marzo de 2001].

Celata, Filippo, y Sanna, Venere S. (2010) "Ambientalismo y (Post)Política en un espacio de reserva: El archipiélago de las Galápagos". Scripta Nova. Revista electrónica de Geografía y Ciencias Sociales, vol. XIV, núm. 331. [Disponible en URL: <http://ub.edu/geocrit/nova/htm>. Consultado el 10 de Septiembre de 2010].

Cordero, Mariano (2006) "Crearon la reserva binacional de biosfera andino norpatagónica". IADE / Realidad Económica. [Disponible en URL: $<$ http://www.iade.org.ar/modules/noticias $>$. Consultado el 13 de Mayo de 2013].

Coronil, Fernando (2000) "Naturaleza del poscolonialismo: del eurocentrismo al globocentrismo", en E. Lander (comp.) La colonialidad del saber: eurocentrismo y ciencias sociales. Perspectivas Latinoamericanas. Buenos Aires: CLACSO, $87-111$.

[Disponible en

URL: $<$ http://bibliotecavirtual.clacso.org.ar/ar/libros/lander/dussel.rtf $>$. Consultado el 12 de Marzo de 2001].

Chiappe, Lucas (2014) "Pretenden declarar a la cuenca de los ríos Puelo y Manso como «zona de sacrificio»". Puerta E [Puesto en línea el 17 de Abril de 2014. URL: <http://www.puertae.com.ar>. Consultado el 24 de Septiembre de 2014]. 
Delgado Ramos, Gian Carlo (2013) “¿Por qué es importante la ecología política?”. Revista Nueva Sociedad, núm. 244, 47-60. [Disponible en URL: $<$ http://nuso.org/media/articles/downloads/3927_1.pdf $>$. Consultado el 13 de Agosto de 2014].

Dussel, Enrique (2000) "Europa, Modernidad y Eurocentrismo", en E. Lander (comp.) La colonialidad del saber: eurocentrismo y ciencias sociales. Perspectivas Latinoamericanas. Buenos Aires: CLACSO, 41-53. [Disponible en URL: $<$ http://bibliotecavirtual.clacso.org.ar/ar/libros/lander/dussel.rtf $>$. Consultado el 12 de Marzo de 2001].

Castro, Iná Elias de (2005) Geografia e Política: território, escala de análise e instituições. Rio de Janeiro: Bertrand Brasil.

Escobar, Arturo (2000) "El lugar de la naturaleza y la naturaleza del lugar: ¿globalización o posdesarrollo?", en E. Lander (comp.) La colonialidad del saber: eurocentrismo y ciencias sociales. Perspectivas Latinoamericanas. Buenos Aires: CLACSO, 113-143. [Disponible en URL: $<$ http://bibliotecavirtual.clacso.org.ar/ar/libros/lander/escobar.rtf $>$. Consultado el 12 de marzo de 2001].

Haesbaert, Rogerio (2007) "Território e multiterritorialidade: Um debate". GEOgraphia, vol. IX, núm. 17, 19-45.

Larraín, Sara (2006) "El agua en Chile: Entre los Derechos Humanos y las reglas del mercado". Polis [En línea. URL: <http://polis.revues.org/5091>. Consultado el 24 de Abril de 2015].

Laurín, Alicia, et al. (2012) La práctica espacial de la integración regional. Desafíos pendientes. Neuquén, Argentina: Editorial Universitaria EDUCO. Universidad Nacional del Comahue.

Leff, Enrique (2005) "La Geopolítica de la Biodiversidad y el Desarrollo Sustentable: economización del mundo, racionalidad ambiental y reapropiación social de la naturaleza", en Seminario Internacional REG GEN: Alternativas Globalizacao (8 al 10 de Octubre de 2005, Hotel Gloria, Río de Janeiro, Brasil). [Disponible en URL: <http://bibliotecavirtual.clacso.org.ar/ar/libros/reggen/pp12.pdf>. Consultado el 20 de Febrero de 2006].

Machado Aráoz, Horacio (2010) "La «Naturaleza» como objeto colonial. Una mirada desde la condición eco-bio-política del colonialismo contemporáneo". Boletín Onteaiken, núm. 10. [Disponible en URL: <www.accióncolectiva.co.ar>. Consultado el 13 de Septiembre de 2014].

Machado Aráoz, Horacio (2011) "El auge de la minería transnacional en América Latina. De la Ecología Política del neoliberalismo a la anatomía política del colonialismo", en H. Alimonda (coord.) La Naturaleza colonizada. Ecología Política y Minería en América Latina. Buenos Aires: Ediciones CICCUS, 135-179.

Martinelli, Luca (2004) "Nuevos desalojos en los Montes Azules. La Reserva de Biosfera, el Corredor Biológico Mesoamericano y el papel de Conservación Internacional”. Boletines del CIEPAC “Chiapas al Día”, núm. 393. 
Pineda, César Enrique (2012) "La dimensión socioambiental del movimiento mapuche en Chile". OSAL, vol. XIII, núm. 32, 135-148.

Porto-Gonçalves, Carlos Walter (2006) A reinvençao dos territórios: a experiencia latino-americana e caribenha. Buenos Aires: CLACSO. [Disponible en URL: $<$ http://biblioteca.clacso.edu.ar>. Consultado el 8 de Septiembre de 2008].

Preciado Coronado, Jaime, y Uc, Pablo (2010) "La construcción de una geopolítica crítica desde América Latina y el Caribe. Hacia una agenda de investigación regional". Geopolítica(s), vol. 1, núm. 1, 65-94. [Disponible en URL: <www.revistas.ucm.es/index.php/GEOP/article/view/GEOP1010120041A>. Consultado el 15 de Febrero de 2011].

Santos, Milton (1996) A natureza do espaço. Técnica e Tempo. Razão e Emoção. Sao Paulo: Editora Hucitec.

Zusman, Perla (2011) Comentarios al trabajo "Revisiones conceptuales asociadas a la nueva territorialidad de la integración". Alicia Laurín, en Cultura y Espacio. Araucanía-Norpatagonia. [Disponible en URL: $<$ http://iidypca.homestead/Publicaciones_IIDyPCA/libro_Cultura_Y_Espacio.ht ml>. Consultado el 15de Abril de 2011]. 